\title{
Reconfiguration of Propulsion System Topology Using Axial Flux Machines in Electric Vehicles
}

\section{Ramesh Babu ${ }^{\text {a }}$, and Mohammad Ferozuddin ${ }^{\text {b }}$}

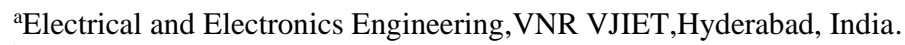
${ }^{b}$ Electrical and Electronics Engineering,VNR VJIET,Hyderabad, India.

Article History: Received: 11 January 2021; Accepted: 27 February 2021; Published online: 5 April 2021

\begin{abstract}
In this paper, an effort is made to reduce the size, weight and cost of Electric Vehicles (EVs) with the reconfiguration of propulsion motor topology. The new machine topology has been advantageously used to replace the conventional motors. A Twin Rotor Axial Flux Induction Machine (TRAFIM) having higher power densities, shorter axial lengths than classical Radial Flux Machines have been implemented in this work. This further reduces the other complexities associated with the mechanical differential which is indented to provide different speeds to two wheels in necessary conditions. The performance of $\mathrm{EV}$ has been remarkably improved with the proposed reconfiguration. This paper presents a comprehensive analysis of an EV with the adoption of Twin Rotor Axial Flux Induction Machine (TRAFIM).
\end{abstract}

Keywords: TRAFIM, EV, Differential, Radial Flux Machine, Axial Flux Induction Motor.

\section{Introduction}

The fluxes representing the stator and rotor of a rotating electrical machine interact on each other and become responsible for the production of torque. Based on the direction of flux in air gap with respect to the axis of shaft, the rotating electrical machines are categorized into Radial Flux Machines (RFM) and Axial Flux Machines (AFM). Though the Axial Flux Machine got invented in 1832 by Faraday, they got less operational opportunities due to certain operational and manufacturing complexities. Simultaneously, the Radial Flux Machines found vast applications for high speed operations (Haung, 1999; Aroulanandam, 2020). The Axial Flux Machines operate at moderately low speeds at high torques and this consideration has become boon for vehicle mobility applications (Metin, 2002).

The Axial Flux Machines are characterized by short axial length and larger diameters whereas the conventional Radial Flux Machines have longer axial length and smaller diameter and it is well depicted in Fig 1. In Radial Flux Machines, the conductor is placed axial to the shaft axis and the flux directs radially between stator and rotor (Latchoumi, 2020). But, in Axial Flux Machines, the conductors are placed radially and the flux direction in air gap is axial to shaft axis (Ramesh Babu, 2012; Ramesh Babu, 2012).

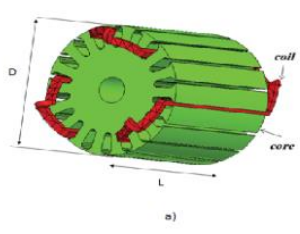

(a)

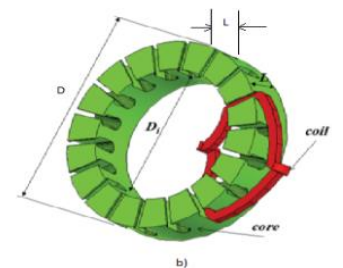

(b)

Figure 1. Radial Flux Machine (a), Axial Flux Machines (b)

The Axial Flux Machines are compact in size, lighter and hence exhibit higher power densities comparatively. These machines can be fabricated in different topologies to have single or multiple air gaps and are illustrated in Fig-2.

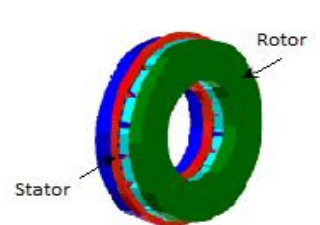

a)

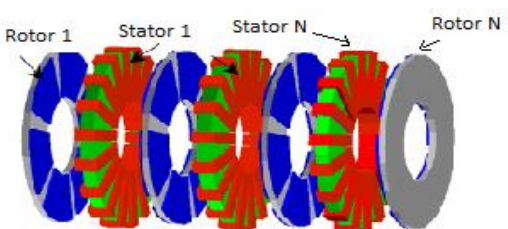

b) 
Figure 2. Axial Machine with a) Single air gap (b) Multiple airgaps

Since permanent magnets are glued on the rotor, the operating speeds are restricted for these machines. The limitations of Radial Flux Machines like the cooling issues, inefficient use of rotor core and the bottle neck for the flux lines at rotor slot root are well addressed by Axial Flux Machines. The other exclusiveness of AFM is high power density. The power density is the ratio of weight to volume of machine which is higher in AFM compared to RFM (Mahmoudi, 2013; Chinnamahammadbhasha, 2020; Pavan, 2020, 2015; Lim, 2016; Balamurugan, 2020; Ellabban, 2010).

The torque produced on different portions of a conductor is not same as the distance from the axis varies to these points AFMs (Balamurugan, 2017). Hence, the torque obtained is average of all these torques. But, the toque produced on different portions of a conductor is same in RFMs as the distance is same from shaft axis to different points on the conductor (Zahra, 2012).

\section{Existing Topology}

The figure 3 depicts the topology of Electric Drive Train conceptually and it is in present use.

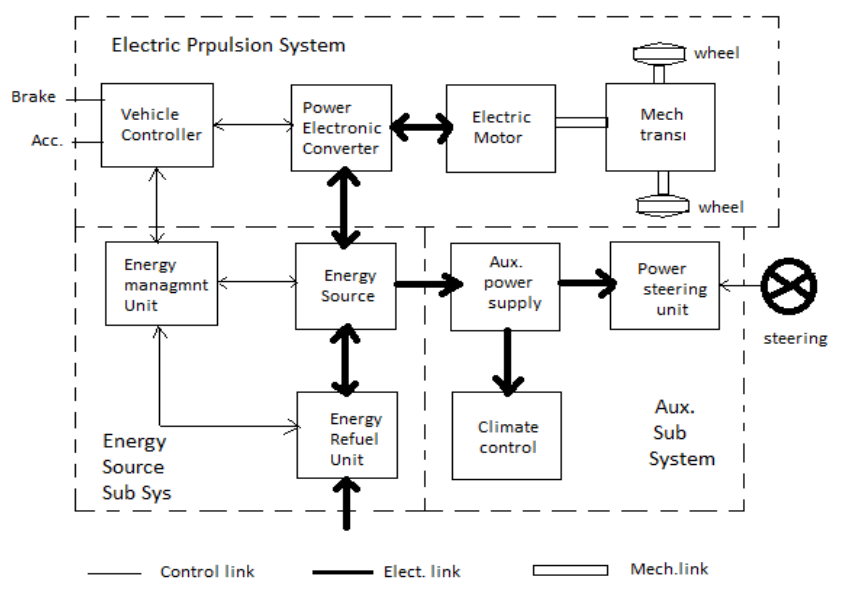

Figure 3. Block Diagram of Electric Vehicle in present use

This majorly consists of three subsystems called Electric propulsion System, Energy storage subsystem and Auxiliary power supply subsystem. Based on the control inputs from brake and accelerator pedals, the vehicle controller provides the required signals to the power electronic converter and it accordingly regulates the flow of power between motor and battery. During the regenerative braking, the power flow is in reverse direction and the energy is restored in the energy sources. The auxiliary power supply feeds power to different EV accessories like climate control and power steering at different voltages. The transmission system sometimes include gear box with differential or only differential. The control signals from the vehicle controllers decide the firing pulses for inverter stack from which controlled voltage is obtained. The purpose of Differential is to create difference in speeds mounted on same shaft/axle. This is needed especially when the vehicle has to take turnings or curves. One wheel has to rotate at different rpm to that of other wheel to cover the distance in same time. Naturally, the outer wheel runs at higher speed and lower torque being the inner one at lower speed and higher torque (Balamurugan, 2020). The power exerted by these two wheels remains same. The Differential is employed not only in vehicles, but also in other applications like Chinese sun dial, mechanical analog computers which perform addition and subtraction.

In the proposed work, the topology of electric propulsion subsystem has been reconfigured. The speed torque characteristics of typical motor used in Electric Vehicle is shown in Fig-4.

During field weakening region, the output power is maintained constant. This is the required region for an electric motor to be used as propulsion system in Electric Vehicles. The speed ratio is the ratio of maximum speed to the base speed. To have high torques at starting or to alter the torque to any desired value in coordination with speed, a gear box is used. As the torque naturally reduces with increase of speed for an electric motor, a gear box of reduced ratio is sufficient in Electric vehicles. 


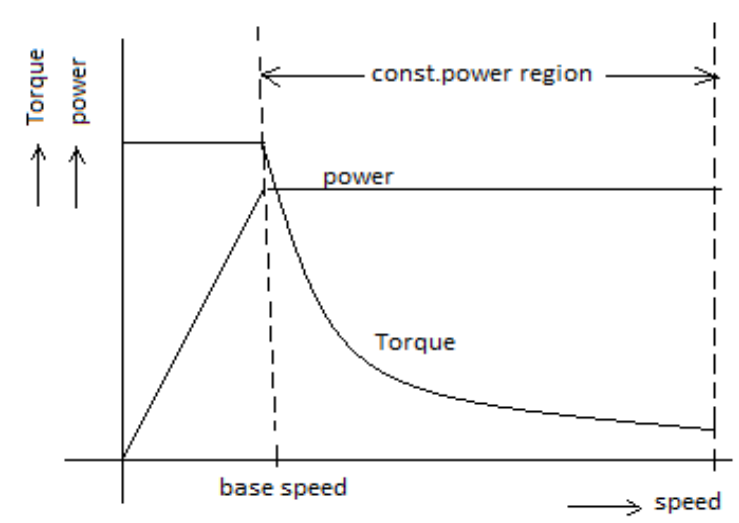

Figure 4. Speed torque characteristics of propulsion motor

During the curved path, the required speeds at two wheels are estimated as follows.

If ' $\mathrm{d}$ ' is the axle length between wheels and $\mathrm{r}_{1}, \mathrm{r}_{2}$ are radii of curves from point of axis, the time taken by two wheels must be same and it is determined as follows

Let $S_{1}$ and $S_{2}$ be the speeds.

$$
S_{1}=\frac{r_{1}}{t}
$$

And $S_{2}=\frac{r_{2}}{t}$

Or $S_{1} r_{2}=S_{2} r_{1}$

If $r_{2}>r_{1}$, then $S_{2}>S_{1}$

The existing system suffers from the following drawbacks:

i. The conventional Radial Machines are more advantageous at high speeds whereas the EV applications require low operating speeds

ii. The conventional mechanical differential contributes for $10-15 \%$ of total system losses

iii. Constraint for differential location

iv. Inefficient utilisation of energy sources.

\section{Proposed Topology}

A Twin Rotor Axial Flux Machine based Power Electronic differential has been suggested in the present work to sweep out the short comings of existing topology (Ezhilarasi, 2020). This proposed novel differential system efficiently and effectively utilizes the energy resources. The twin rotors are exactly identical in physicality and performance and make the same sense of real twins. The block diagram which shows the reconfiguration of Electric Vehicle System is shown Fig-4.1.

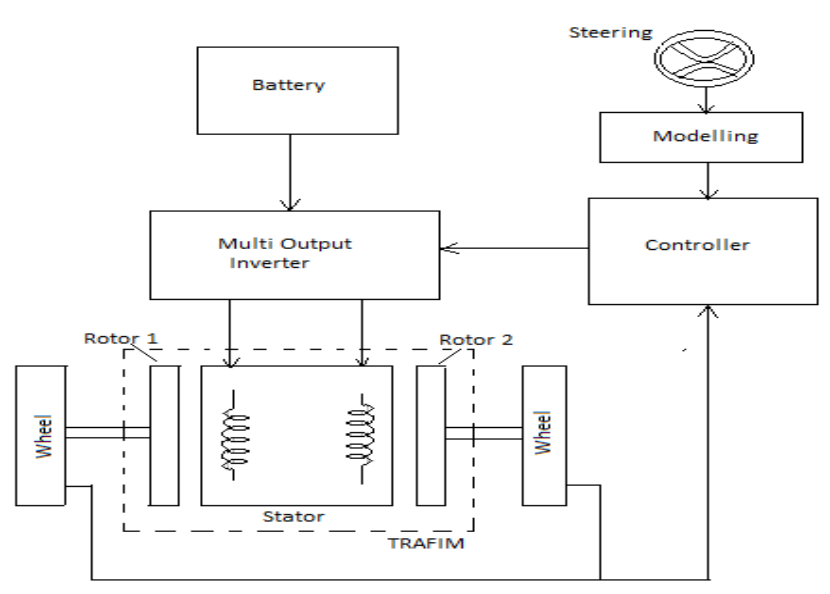

Figure 4.1. Block Diagram of Proposed Topology. 
The multi-output Inverter feeds the two sets of three phase windings placed on the stator of Twin Rotor Axial Flux machine (Rahim, 2020; Garikipati, 2021; Arunkarthikeyan, 2021; Subapriya, 2020) . The two rotors are coupled to two wheels through two independent shafts. The delivers the required voltages and frequencies to the stator windings in accordance with control signals supplied by the controller. The controller is fed with the actual wheel speeds and the steering positions after having done the required modeling.

\section{Modelling of Trafim}

To carry out any sort of analysis in quantitative form on electric machines, their mathematical models are generally considered. As the stator and rotor magnetic axes of a dc machine act at right angle and stationary with respect to each other, the process of obtaining its mathematical model is comparatively an easy task. In case of three phase induction machines, there are three windings on stator and three windings on rotor. Their magnetic axes are mutually displaced by $120^{\circ}$. Hence, its mathematical model involves complex voltage equations having variable parameters. To avoid these complexities, Linear Transformations are used. The Linear Transformations include Phase transformation and Active Transformations. Phase transformations are used to convert three phase system or $(a, b, c)$ system into two phase system or $(\alpha, \beta)$ system being total power and mmf are maintained constant.

$\left[\mathrm{V}_{\alpha \beta}\right]=[$ Transformation matrix $]\left[\mathrm{V}_{\mathrm{abc}}\right]$

The Active Transformation is used to convert $(\alpha, \beta)$ system into a $\mathrm{d}$-q model or model to a common reference frame.

The voltage equations of a single air gap axial flux induction machine are

$V_{d s}=i_{d s} R_{s}+\Psi_{d s} i_{d s}$

$V_{q s}=i_{q s} R_{s}+\Psi_{q s} i_{q s}$

$V_{d r}=i_{d r} R_{r}+\Psi_{d r} i_{d r}$

$V_{q r}=i_{q r} R_{r}+\Psi_{q r} i_{q r}$

The electromagnetic torque equation for single air gap axial flux induction motor is identified as

$$
T_{e}=\frac{3}{2} \frac{p}{2} L_{m}\left\{i_{d s} i_{q r}-i_{q s} i_{d r}\right\}
$$

The mathematical process has been extended to Twin Rotor Axial Flux Induction Machine and the voltage equations are

$V_{d s}=i_{d s} R_{s}+\Psi_{d s} i_{d s}$

$V_{q s}=i_{q s} R_{s}+\Psi_{q s} i_{q s}$

$V_{d r 1}=i_{d r 1} R_{r}+\Psi_{d r 1} i_{d r 1}$

$V_{q r 1}=i_{q r 1} R_{r}+\Psi_{q r 1} i_{q r 1}$

$V_{d r 2}=i_{d r 2} R_{r}+\Psi_{d r 2} i_{d r}$

$V_{q r 2}=i_{q r 2} R_{r}+\Psi_{q r 2} i_{q r 2}$

The electromagnetic torque for twin rotor motor is calculated as

Table 1. Motor Parameters

\begin{tabular}{|c|l|}
\hline$V_{d s}, V_{q s}$ & Stator voltages in d-q frame \\
\hline$V_{d r 1}, V_{q r 1}$ & Rotor 1 voltages in d-q frame \\
\hline$V_{d r 2}, V_{q r 2}$ & Rotor 2 voltages in d-q frame \\
\hline$\Psi$ & Flux linkages \\
\hline
\end{tabular}




\begin{tabular}{|l|l|}
\hline$p$ & Number of poles \\
\hline$i$ & Current \\
\hline$L_{m}$ & Mutual Inductance \\
\hline
\end{tabular}

\section{Simulation Results}

To carry out the simulation studies to access the performance of the power electronic differential in EV, a software package called VEHICLE-SIMULATOR X has been used. The results are presented in Fig-5.

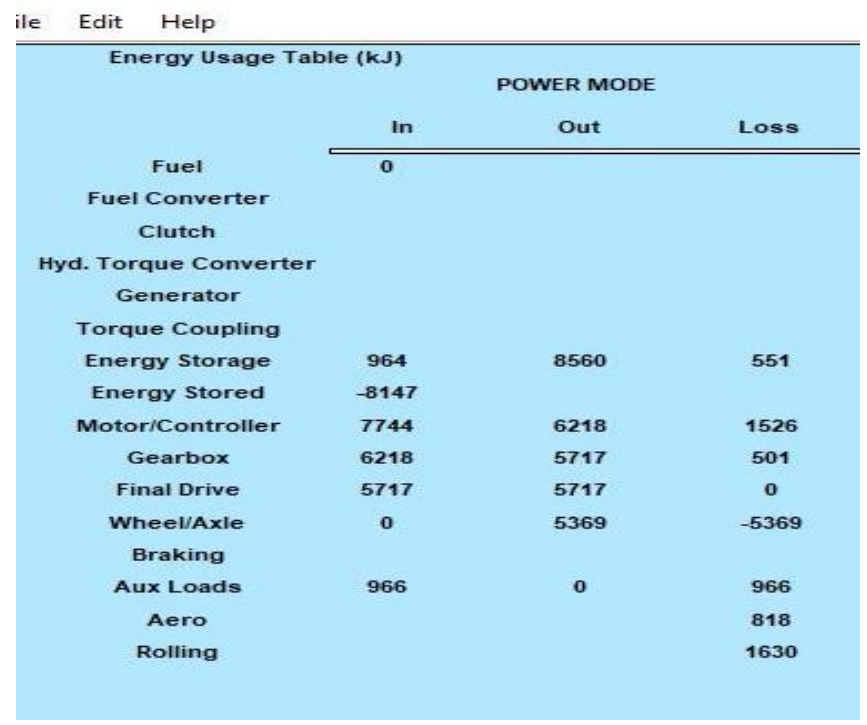

Figure 5. Energy usage in EV

The stator and rotor currents and electromagnetic torques of TRAFIM to synchronous reference frame are shown in figures 5.1 to 5.3.The Fig-5.1 shows the Stator currents in d-q frame and rotor1 currents in d-q frame. Fig-5.3 shows the torque waveform obtained when multi air gap machine is modeled through MAT-LAB code.

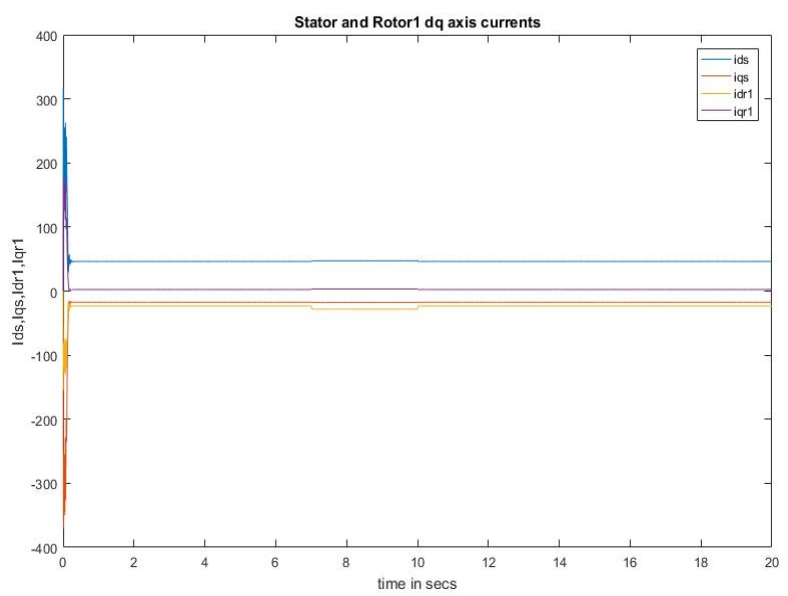

Figure 5.1. Stator and rotor 1 currents in $\mathrm{d}-\mathrm{q}$ axes

$$
T_{e}=\frac{3}{2} \frac{p}{2} L_{m}\left\{i_{q s}\left\{i_{d r 1}+i_{d r 2}\right\}-i_{d s}\left\{i_{q r 1}+i_{q r 2}\right\}\right\}
$$

Fig-5.2 shows the stator and rotor 2 currents in $d-q$ frame. 


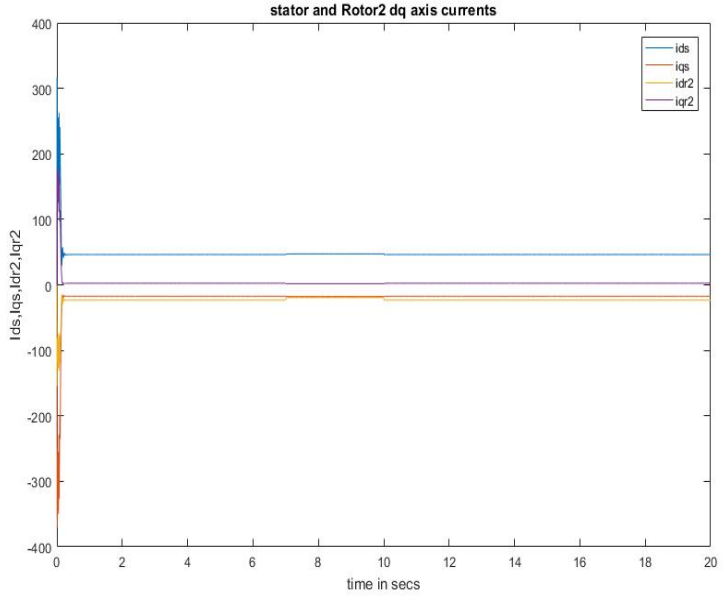

Figure 5.2. stator and rotor 2 currents

\section{Validation of results}

The torque obtained by writing MAT-LAB code is validated when single rotor motor is fed through Inverter based on the concept of Field Control using the Simulink Models in MAT-LAB. Fig-6 shows the torque obtained when d-q transformation theory is applied for field control of motor.

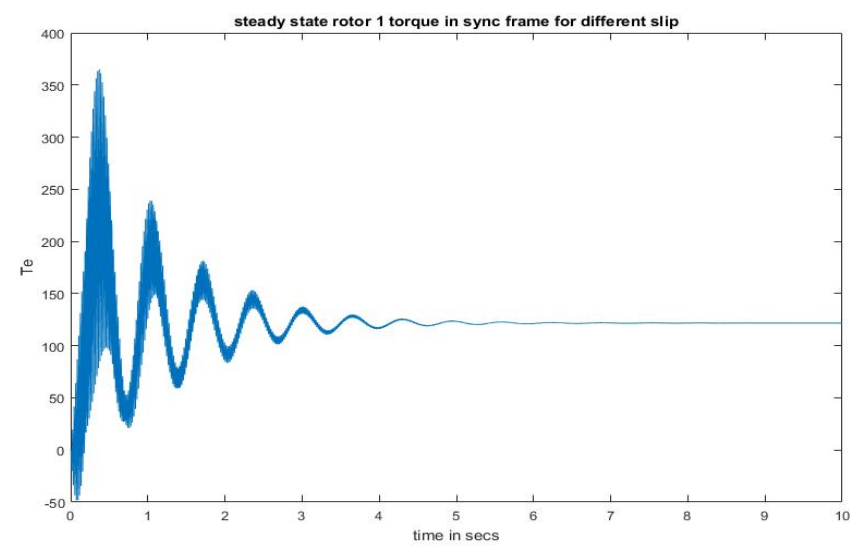

Figure 5.3. (a).Rotor 1 torque in synchronous d-q frame 


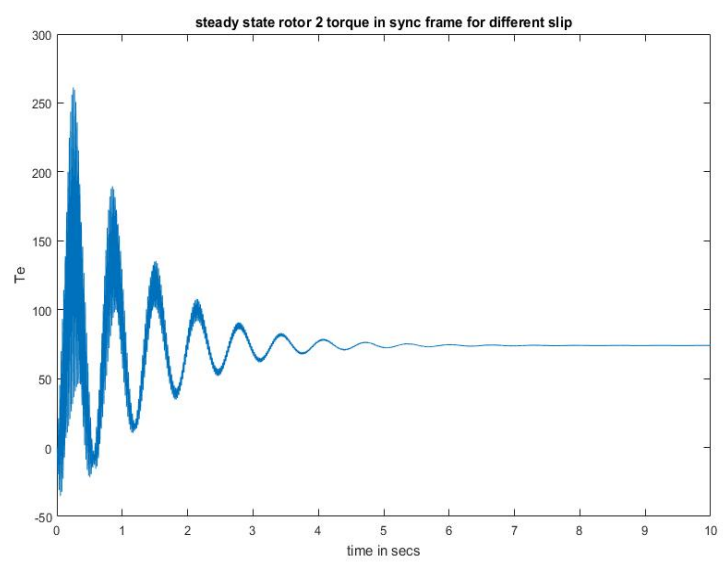

Figure 5.3. (b) Rotor 2 torque in synchronous d-q frame

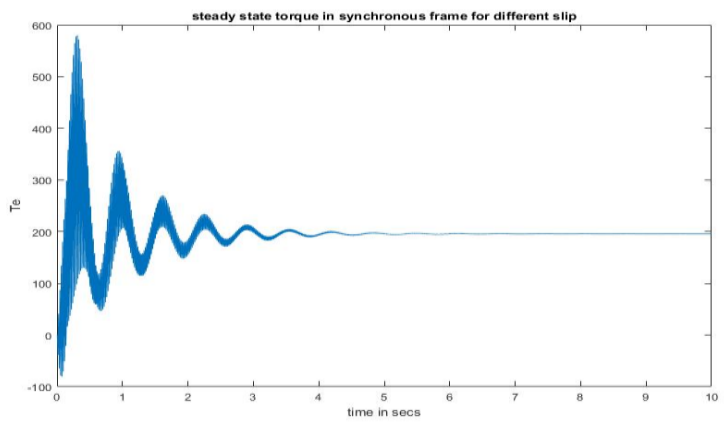

Figure 5.3. (c) Instantaneous final torque of rotors at shaft

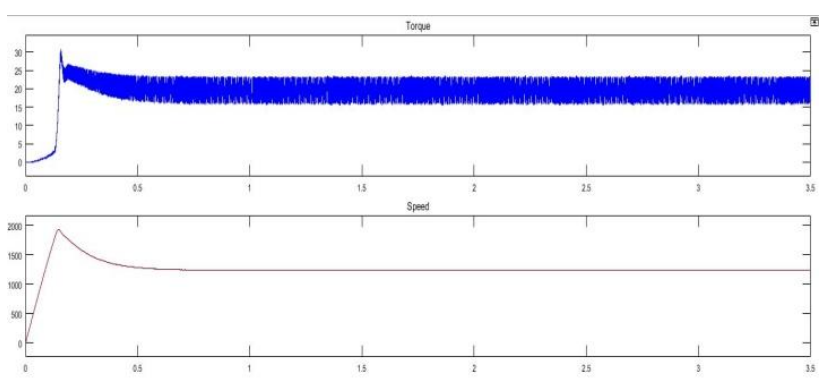

Figure 6. Torque and speed with Field Oriented Control

\section{Conclusions}

This paper highlights the advantages of Axial Flux Machines like reduced size, reduced weight and low cost for Electric Vehicles (EVs) applications. The configuration of EV has been completely modified with TRAFIM as propulsion motor. These machines have shorter axial lengths and have higher power densities when compared to conventional Radial Flux Machines. This topology further reduces the complexities associated with the mechanical differential. The mathematical model of TRAFIM has been obtained to synchronously rotating reference frame and the stator and rotor currents are instantaneous. The topology of EV has been reconfigured with use of TRAFIM. With the proposed topology, the position of differential and space occupied by the propulsion motor is reduced since axial machines are compact in size. With the proposed configuration, transmission system is eliminated as two rotors of axial motor resemble like wheels and can be used as wheels for electric vehicle.

\section{References}

2. Aroulanandam VV, Latchoumi TP, Balamurugan K, Yookesh TL. (2020) Improving the Energy Efficiency in Mobile Ad-Hoc Network Using Learning-Based Routing, Revue d'Intelligence Artificielle, Vol 34(3), pp. 337-343, 2020.

3. Arunkarthikeyan K., and Balamurugan K. (2021) Experimental Studies on Deep Cryo Treated Plus 
Tempered Tungsten Carbide Inserts in Turning Operation. In: Arockiarajan A., Duraiselvam M., Raju R. (eds) Advances in Industrial Automation and Smart Manufacturing. Lecture Notes in Mechanical Engineering. Springer, Singapore. https://doi.org/10.1007/978-981-15-4739-3_26.

4. Balamurugan K. (2020) Metrological changes in surface profile, chip, and temperature on end milling of M2HSS die steel. International Journal of Machining and Machinability of Materials, 22(6):pp. 443-453.

5. Balamurugan K and Uthayakumar M, (2017) Preparation And Machining Studies Of Lapo4 Y2o3 Ceramic Matrix Composite, http://hdl.handle.net/10603/166221.

6. Balamurugan K, Uthayakumar M, Sankar S, Hareesh US, Warrier KG. (2020) Process optimisation and exhibiting correlation in the exploitable variable of AWJM. International Journal of Materials and Product Technology, 61(1), pp.16-33.

7. Chinnamahammad bhasha A, and Balamurugan, K. (2020) Fracture analysis of fuselage wing joint developed by aerodynamic structural materials." Materials Today: Proceedings, Vol.38, pp. 2555-2562

8. Ellabban, O., Mierlo, J. V., Lataire, P. (2010) A new closed loop speed control of induction motor fed by a high performance Z-source inverter," 2010 IEEE Electrical Power \& Energy Conference, Halifax, NS, $2010: 1-6$.

9. Ezhilarasi TP, Dilip G, Latchoumi TP, Balamurugan K. (2020) UIP-A Smart Web Application to Manage Network Environments. InProceedings of the Third International Conference on Computational Intelligence and Informatics, pp. 97-108. Springer, Singapore.

10. Haung, S., Luo, J., Loenardi, F., Lipo, T.A., (1999) A comparison of power density for axial flux machines based on the general purpose sizing equations". IEEE tarns. Energy conversion, 14:185-192.

11. Lim, D., Cho, Y., Ro, J., Jung, S., Jung, H. (2016) Optimal Design of an Axial Flux Permanent Magnet Synchronous Motor for the Electric Bicycle," in IEEE Transactions on Magnetics, 52 (3):1-4.

12. Latchoumi TP, Reddy MS, Balamurugan K. (2020) Applied Machine Learning Predictive Analytics to SQL Injection Attack Detection and Prevention. European Journal of Molecular \& Clinical Medicine.;7(02), pp. 3543-3553.

13. Metin Aydin, Huang, S., Thomas Lipo, A. (2002) A new Axial Flux surface mounted permanent magnet machine capable of field control", Industry application conference,37th IAS Annual meeting, conference record, 2: 1250-1257.

14. Pavan MV, Balamurugan K, Balamurugan P. (2020) Compressive test Fractured Surface analysis on PLA-Cu composite filament printed at different FDM conditions. InIOP Conference Series: Materials Science and Engineering, Vol. 988,pp. 012019. IOP Publishing.

15. Platt, D., Smith, B.H. (1993) Twin rotor drive for an electric vehicle” IEEE PROCEEDINGS-B, 140 (2).

16. Ramesh Babu, V., Soni, M.P. (2012) A Novel Method of Using Twin-Rotor Axial Flux Induction Machine for Wind Energy Conversion and the Reactive power Compensation by TSC-TCR" International Journal of Emerging Technology and Advanced Engineering (IJETAE) ISSN 2250-2459, 2 (8):399-407.

17. Ramesh Babu, V., Soni, M.P., Manjeera, Ch. (2012) Modelling of Axial flux Induction machine with sinusoidal winding distribution” 2012 Annual IEEE India conference (INDICON), :481-486.

18. Garikipati P, and Balamurugan K. (2021) Abrasive Water Jet Machining Studies on AlSi 7+63\% SiC Hybrid Composite. InAdvances in Industrial Automation and Smart Manufacturing, pp. 743-751, Springer, Singapore.

19. Zahra NG., Hamid L. (2012) A Survey on Axial Flux Induction Motors" PRZEGLADD ELEKTROTECHNICZNY (Electrical Review), ISSN 0033-2097, R. 88 NR 2/2012. 